and this has received excellent confirmation from Prof. Hall's observations in $\mathbf{1 8 7 7}$, which indicated a period of roh. $14 \mathrm{~m} .28 \cdot 8 \mathrm{~s}$. Schroter also glimpsed several spots indicating periods of about twelve hours, but these observations are probably erroneous, as they differ so widely from the corroborative results of Herschel and Hall. But it is possible that these distinctive markings on Saturn give anomalous periods similarly to the spots on Jupiter, though hardly to the extent of the differences between the existing observations. Were this planet more sedulously observed, it is certain that wc should obtain some new and interesting facts with reference to his globe and rings. As to the belts, they are occasionally very plain; Grover has seen them with only 2 inches of aperture, and the writer distinguished them well in $188 \mathrm{r}$ with a $2 \frac{1}{2}$-inch $\mathrm{O} . \mathrm{G}$. What, therefore, can be so readily seen in small tclescopes ought to come out with considerable detail in the large instruments of the present day. As to the system of rings, it forms a complicated object for study. The marked differences in their tints and brightness should be recorded on all occasions. Cassini's division is always plain, but the outer and more minute division of Encke has sometimes defied the power of our best telescopes. It apparently varies both in position and intensity. Other faint subdivisions are sometimes traced, but they are very difficult objects, and seldom seen with ccrtainty. The crape or gauze ring, together with other details, such as the anomalous shadow of the ball upon the rings, supply an endless store of curious appearances requiring further elucidation.

There is no doubt that, notwithstanding the mass of interesting facts gleaned in past years respecting the physical aspects of Mars, Jupiter, and Saturn, there remain many novel features to be distinguished, and many new facts to be descried. Observers, therefore, who make these observations a specialty should endeavour not only to confirm former results, but to make some advance upon our existing knowledge.

We have not space in the present paper to refer to the satellites of these several planets, but may possibly be able to do so on a future occasion. W. F. DENNING

\section{THE INTERNATIONAL BUREAU OF WEIGHTS AND MEASURES ${ }^{1}$}

\section{II.}

$\mathrm{H}$ AVING now given a description of the instruments used in the section of linear standards, we come to the apparatus belonging to the section of standards of wcight.

As regards the essential instrument connected with the process of weighing, the International Bureau posscsses one of the most remarkable collections of balances of precision cxisting in the world. Of these the principal ones have been constructed by the house of Ruiprecht of Vienna. The large engraving accompanying this (Fig. 3) represents in its entirety the spacious chamber in which they are set up. In addition we gave a special sketch ( $p$. 465 , Fig. 2) of the balances principally designed for conparison of standard kilogrammes. This balance is constructed in such a manner as to adapt it for being worked at a distance, whereby it is kept free from the disturbing influence always occasioned in the process of weighing by the proximity of the observer, in consequence of the variations of temperature which his presence close to the balance gives rise to. In the case of the instrument now in question, the observer, having prepared his weighing apparatus the preceding day, - that is, placed the weights he will have occasion to use in their right positions in the pans of the balance,--avoids any longer going near the blance. Standing in front of his telescope he performs all the operations involved in weighing that is, he puts the weights on the pans, releases the pans, and then the S. Continued from p. 466 . beam, and measures the oscillations of the beam; then changes the weights from one side to the other, placing that to the right which was at the left, and conversely, \&c., the whole at a distance of four metres. For that purpose the balance is provided with a mechanism very ingenious and of perfect precision which works automatically by means of handles fixed to the extremity of long rods. The oscillations of the beam are read by the reflection of a graduated scale on a mirror borne by the beam; it is the image of that scale the observer sees displacing itself slowly in his telescope while the balance oscillates. He notes a certain number of successive oscillations, and thence calculates the position of equilibrium.

Three other balances, of the same model but smaller, are intended for comparisons and adjustments of lighter weights. They have the same mechanism of transposition, only in the case of the two smallest, a little more simplified and less complete. In the centre of the large engraving (Fig. 3) are seen the large armis of the lever which allow the weighings to be made at a distance. These arms rest on three stone pillars, above which are placed the telescopes for reading the oscillations of the beam.

The following are some details of the mechanism of transposition employed in this balance. The pans of the balance have a shape altogether peculiar. Each is formed by a circular piece open at one point and extending itself inwards by four triangular plates or teeth directed towards the centre of the balance. A cross piece placed underneath can be passed between these plates. Suppose now that weights, say of one kilogramme each, are placed above the pans on each side; and to make the idea the more definite let the kilogramme $A$ be on the left scale and the kilogramme $B$ on the right. Taking hold of one of the four handles under his hand, the observer sets the mechanism in motion. This is what happens :-the cross piece placed under the pan mounts at first, ascends beyond the plane of the pan and consequently lifts the kilogramme resting above it. Arrived at a suitable height the cross piece shifts its place laterally, and disengaging itself from the pan it gradually gets deposited above one of the plates, attached right and left to the pillar of the balance. These plates follow an arrangement analogous to that of the pans. By continuing the movement the cross piece then commences to descend, and traverses the plane of the plate, depositing on it the kilogramme which it has raised from the scale. While these movements are effected to the left in the case of the kilogramme $A$, they are in simultaneous accomplishment to the right in the case of the kilogramme B. 'The two weights to be compared are thus transferred at the same time to the central plates. Then taking hold of a second handle the observer turns the two plates $180^{\circ}$ round the axis of the pillar of the balance, a movement which shifts the plate which was at the left to the right, and conversely. All that is needed then is to cause the same evolution to be gone over again with the crosses which they have already done, but inversely, in order to bring back the kilogrammes to the scales of the balance; the kilogramme $A$ is then at the right, the kilogramme $B$ at the left, and the observer can proceed to the second part of the weighing.

The two other handles control-one the movement serving to release the pans, the other the movement low ering the fork and setting free the beam.

For a long time it has been known that the balance is an instrument of precision par excellence. By means of those herc in question the minimum amount of error in the process of weighing has been reduced to an almost infinitesimal degree. The difference of two kilogrammes, for example, can by them be determined to a nicety reaching to the hundredtb of a milligramme, that is, the weight of a kilogramme is ascertained down to within a hundred millionth of its absolute value.

In another part of the hall is shown the hydrostatic 
balance serving to determine densities ; and here, again, details of operations have been perfected up to the last limits compatible with the actual state of science. The water which is to be used for hydrostatic weighings, having been once distilled by an ordinary still, is redistilled by means of an apparatus of platinum, and then re-collected in a platinum vase. The latter is placed under the balance employed for the weighings, and by a series of ingenious apparatus the weights can be plunged in the water and all the manipulations performed,-manipulations often very delicate, but indispensable if all possible chances of error are to be reduced to a minimum.

The weighing section contains, besides, a beautiful collection of weights, -in platinum, iridium, and in quartz for weights of the first class, and in gilt brass for weights of the second class.

Irrespective of the fundamental apparatus we have just mentioned, the bureau possesses a large number of different instruments; some intended for certain special labours, others necessary for accessory processes in close connection with operations of comparisons or of weighings. Among the former, one of the most remarkable, by reason of the exceeding delicacy of the method it sets in operation, is the Fizeau apparatus, by means of which expansions in small standards, or fragments of some millimetres in thickness, are measured by applying an optical process founded on observation of the phenomenon of the interference of light. This apparatus enables variations of distance between two points to be determined and measured down to some millionths of a millimetre.

The accessory instruments are cathetometers, spherometers, meteorological instruments, barometers, thermometers, hygrometers, \&c. Fig. 4, for example, shows the normal barometer of the section of weighings, a splendid instrument combining all the most perfect contrivances for the measurement of atmospheric pressures with the utmost possible degree of accuracy.

The measurement of temperature plays an essential part in all operations which bave to be performed with standards either of length or of weight; the studies in connection with the thermometer have likewise a place so important that they may be regarded as constituting a section by themselves, with instruments peculiarly their own.

The measurement of temperatures does not form a separate section in the International Bureau, but the importance of the operations connected with it and the precision of the apparatus employed for this end entitle it to a special description.

The air thermometer depends on a remarkable principle, the knowledge of which science owes to the classical experiments of Regnault on the expansion of gas. The illustrious physicist has in effect demonstrated that the increase of tension which gas suffers when heated while its volume is kept constant is sensibly proportional to the temperature.

It is easy to conceive that Regnault utilised this property for the measurement of temperatures. The first air thermometer of precision constructed by him consisted essentially of a glass globe filled with air, connected by a capillary tube with one of the arms of a mercurial manometer. Special contrivances allowed the mercury to be constantly maintained at the same height in this arm, while the globe was exposed to different temperatures. The tension of air at each temperature is then measured by the height of the mercurial column balancing it.

This instrument, generally employed by experts, has subsequently undergone numerous modifications, the most of which aim at imparting greater precision to the measurement of pressures. This measurement, which consists in determining the difference of the height of the mercurial level in the two arms of the manometer, really presents great difficulties, seeing that tubes of large dimensions are cmployed for the manometer, a condition necessary to avoid the capillary depression of the mercury. The surface of the mercury in the large tubes presents a plane superficies, so smooth that it is impossible to distinguish the level of the mercury when it is viewed horizontally. To attain this end, one makes use of movable points, bringing them gradually close to the surface. Observing, then, in a telescope the level of the mercury, the point is seen drawing nearer and nearer its image; the instant of contact between the movable point and its image indicating exactly the level of the mercury.

The apparatus represented in Fig. 4 is the one which has been constructed at the observatory of the International Bureaul. The arrangement we have just spoken of has been adopted as much for the sake of the readings of the manometer as of the measurement of the atmospheric pressure in the normal barometer, $\mathrm{B}$ B. In the part to the left of the diagram, one distinguishes in $\mathrm{A}$ the arm of the manometer which is connected by a capillary tube with the globe placed in the interior of the warming apparatus. The latter has been placed in an adjoining position, in order not to expose the measuring apparatus to variations of temperature.

Having determined the normal positions of the instruments, one can proceed to the comparison of the mercurial thermometers, $t t$, the reservoirs of which are placed in the warming apparatus in proximity to the globe, A, of the air thermometer. The observations consist in reading on one side the temperature indicated by the mercurial thermometers, and on the other in measuring the difference of the mercurial level in the two arms of the manometer; the open arm of the latter experiences the atmospheric pressure, the manometer merely indicating the difference between the atmospheric pressure and the tension of air inclosed in the globe. To get the total pressure balancing the tension of the air in the globe, the barometric pressure must be added to that indicated by the manometer. The measurement of the pressures is effected by means of three horizontal telescopes, movable vertically through the length of the upright fixed to the pillar shown on the left side of the diagram. This upright is able to turn on its axis. Having adjusted the level of the mercury, one can turn the telescopes, without deranging them, round this vertical axis in such a manner as to read the graduations on the scale attached to the adjacent manometer. The telescopes fixed on the upright form to some extent, a pair of beam compasses, as they allow the difference of the mercurial level in the arms of the manometer to be transferred to the scale serving to measure it.

These instruments are easily adequate to the measurement of a hundredth of a millimetre. In the ordinary conditions of experiments three hundredths of a millimetre correspond with a variation of temperature of one hundredth of a degree Centigrade. To maintain the temperature constant within these limits, the steam of different liquids, such as water, ether, methylic alcohol, ordinary alcohol, the ebullition of which takes place at continuous temperatures, is used with advantage. The regular ebullition of these liquids being one of the conditions essential to the constancy of the temperature, the arrangement indicated in the diagram has been decided on. A vessel, $a$, placed in a water-bath, $c$, contains the liquid, the steam of which escaping by the tube $x x$, penetrates into the double cased heating apparatus. Having traversed all the parts of the apparatus, including the glass tubes in which the mercurial thermometers $t t$ are placed, the steam issues by the tubes $y y$ to liquefy in the condenser $R$, whence the liquid returns to the vessel by the tubes A. Other tubes serve equally to return to the vessel so much of the steam as becomes condensed on the way or in the apparatus, so that the same quantity of liquid will serve for a sufficiently long time. The waterbath $c$, which supplies the heat necessary for keeping up the boiling of the liquid employed, is itself heated by 


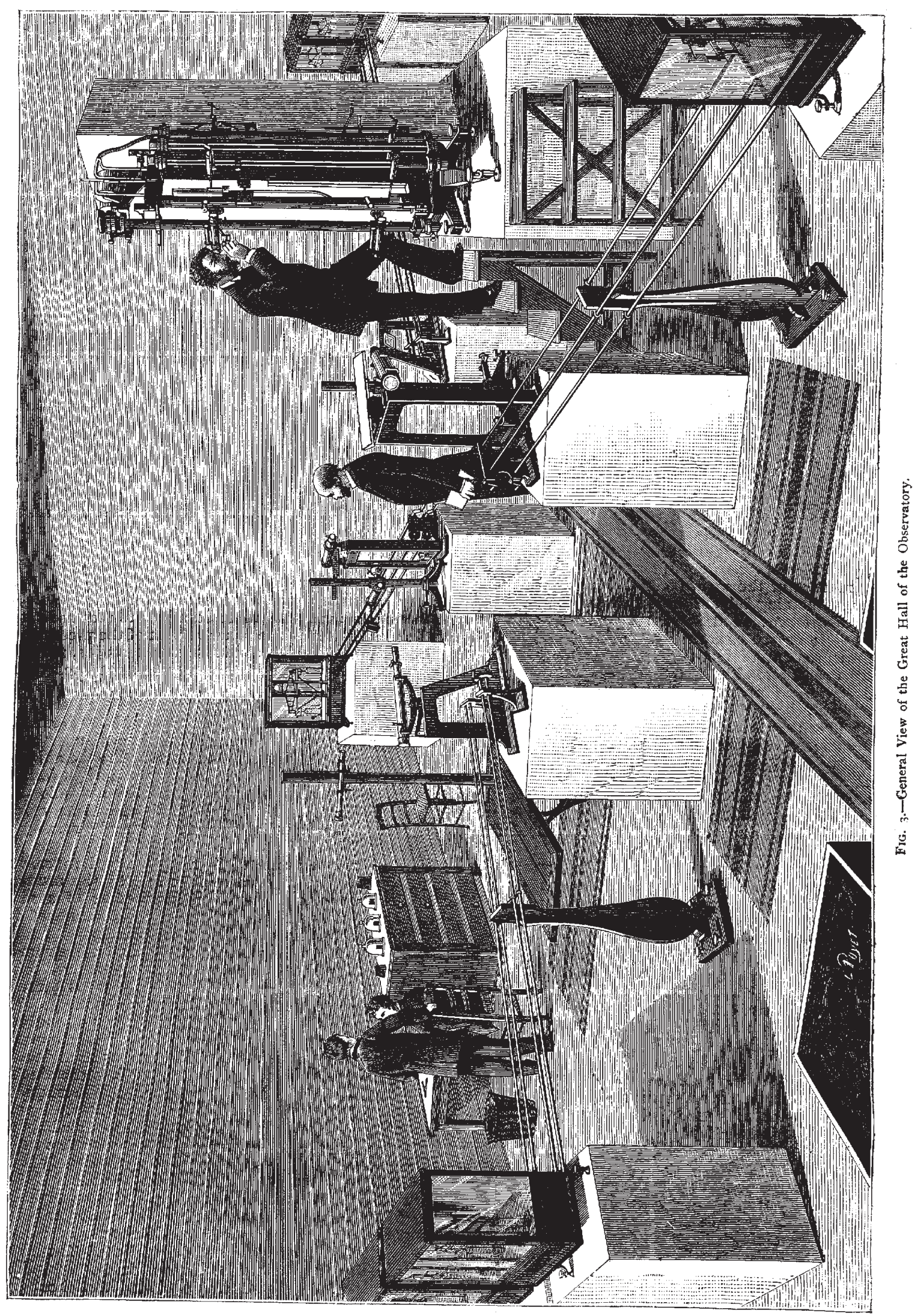


the steam from a little copper, $f$, placed at some distance from it.

The arrangements we have just briefly described enable a difference of readings between the air thermometer and the mercurial thermometer to be determined to nearly the hundredth of a degree.

From the descriptive summary thus given it will be seen how important is the new and remarkable international establishment now really established in the neighbourhood of Paris. It remains to add a word regarding the benefits which the labours of this institution are calculated to yield and the phases they have actually assumed.

The signing of the Metre Convention of 1875 will necessarily be followed in the near future by the adoption of the metric system on the part of all the nations of the civilised world. The universal introduction of a uniform system of weights and measures, by establishing a new bond between people and people, and by promoting international relations, will undoubtedly prove a powerful factor in the interests of civilisation. This, however, is not the only, nor even, the principal, interest of this international work. It was not necessary, it may be properly asserted, for the purposes of commerce and industry, to create a collection of such complex and perfect instruments and machines. More than anything else the interest of the labours of the bureau is scientific. Science will more and more cease to rest content with close approximations ; in all possible branches it craves rigorous exactitude, it aims at precision. The International Bureau will furnish science not only with standards of measurement exactly controlled and verified, but also with a great number of physical constants determined with the greatest care and under conditions as perfect as possible.

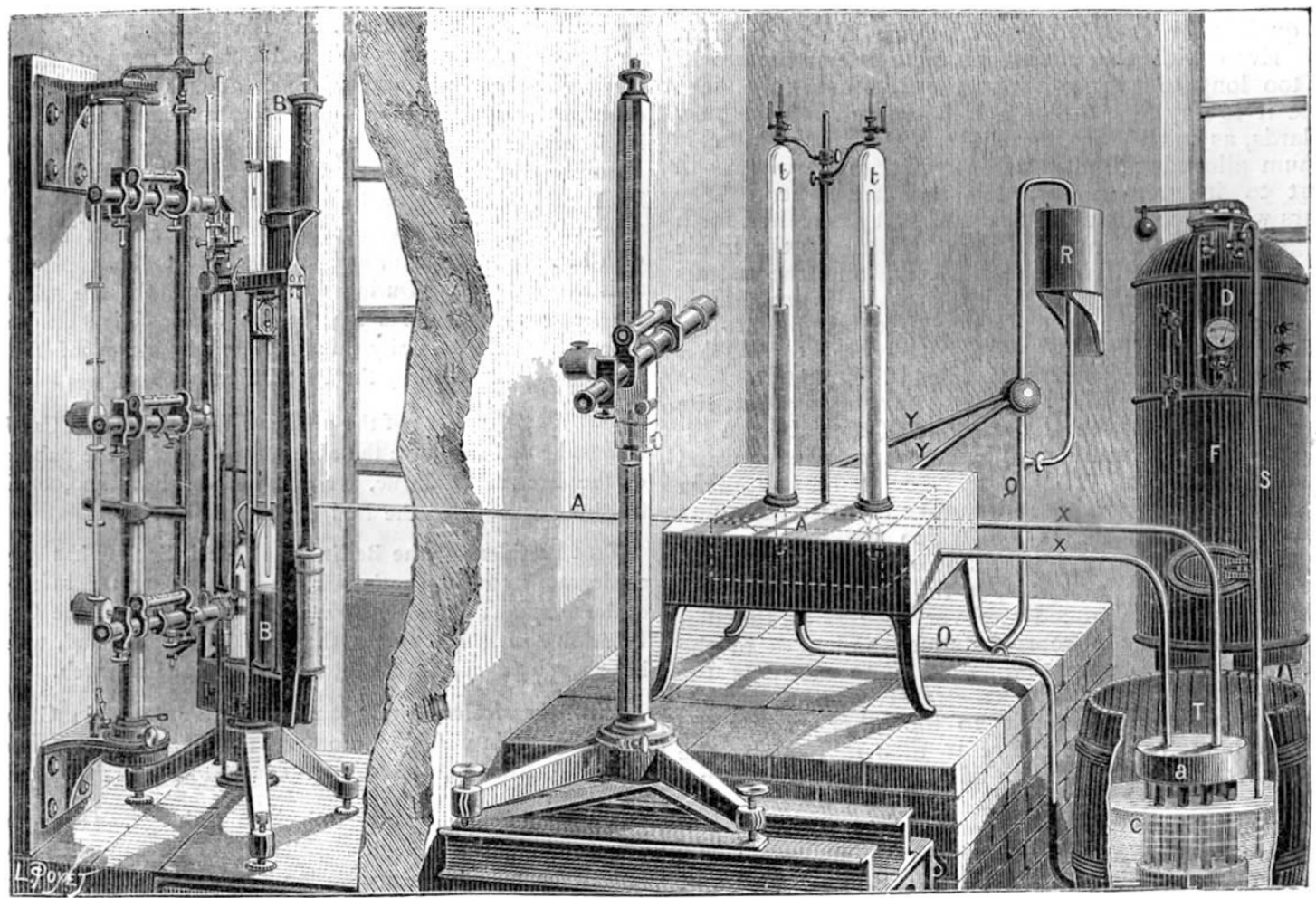

FIG. 4.-Apparatus for Measurement of Temperature and Barometric Pressire.

Among all the sciences the one which will reap the greatest benefit from the new institution is geodesy. In fact one of the greatest drawbacks to an exact knowledge of the figure of our globe is just the uncertainty still prevailing in regard to the relative values of the measures which, having been employed for the measurement of the different bases, have served as points of departure for triangulations executed on various points of the earth's crust. The minute study of these measures, centred henceforth in the laboratories of Breteuil, will assuredly cause the troublesome discrepancies to vanish, and will offer a surer basis for the labours of geodesists. As much may be said for the study of the variations of gravity by means of the pendulum. The International Commission have deeided on taking as the point of departure for the new metric units the standards already existing, that is, the metre and the kilogramme of the archives of France in their actual state. This decision ought to receive unqualified approval. While rendering full homage to the great and valuable idea, formed at the end of last century, that the basis of universal measurements must be sought in the dimensions of the globe occupied by the human race, it ought also to be understood that for the present day the pith of the matter does not centre in the metre being a few microns (millionths of a millimetre) longer or shorter. The great point is that the whole world possess the same metre, and that the copies distributed be all perfectly equal to the standard, or rather rigorously determined in relation to that standard. To demand over and above that the length of the metre tally exactly with its theoretic definition would assuredly be demanding that the metre be subjected to periodical retouchings and modifications in order to make it keep pace with the progress of science, which would be the very worst of inconveniences for a fundamental unit.

This point settled, the next thing was to make an international metre and kilogramme,-copies, viz. as exact as possible of the metre and the kilogramme of the archives, 
but presenting a greater guarantee than the originals in regard to their indefinite conservation and precision of comparisons, and which, being the common property of all the signatory nations of the Convention, should be preserved at the International Bureat, and serve henceforth as prototypes and points of departure in the system of weights and measures for the entire world.

The task next following was to make a sufficient num. ber of metres and kilogrammes for distribution among the contracting Governments, after they had been compared with the international standards.

The choice of the material of which the new standards should be constructed, the form to be imposed on them, the nature and arrangement of the designs, the processes to be employed in the comparisons, and a host of accessory questions connected with the preceding mattershave all been the subject of long and learned deliberations, in which, besides the International Committee, the French section of the International Commission, composed of the best qualified French authorities, have played a great part. Even with the utmost possible brevity it woukd take too long to pass each of these points in review. Suffice it to say that the material adopted for the new standards, as much for the metre as the kilogramme, is platinum alloyed with a tenth part of iridium, which will impart to it greater hardness and resistance. The labours which the choice of this material has called forth have given rise to remarkable improvements in the mode of working and purifying the platinum and the metals with which it is found allied in the ore. It is impossible to recall them without at the same time bringing to remembrance Saint-Claire Deville, who with indefatigable zeal devoted the last years of his life to this pursuit.

The form fixed on for the metre is that of a bar, the section of which has the shape of an $X$ or rather an $H$, the legs of which would straddle towards the top and towards the bottom. This form, calculated to supply a maximum rigidity for a given quantity of material, offers various other advantages on which we cannot now enlarge. It is $\mathrm{I} \cdot 02 \mathrm{~m}$, in length, and on the upper surface of the transversal limb (that is, on the neutral surface of a deflected beam) are traced two very fine lines, the distance of which at zero represents just the length of the metre. It is then a metre is traits. The metre of the archives, on the other hand, is a metre $a$ bouts, that is, a bar measuring from one extremity to the other exactly the length of a metre. The metre is then defined by the distance at zero between the middles of the two terminal planes.

The comparisons between the international metre and the metre of the archives have been made at the Conservatoire des Arts et Métiers; those between the international kilogramme and the kilogramme of the archives have been made at the Observatoire. These labours, lasting no less than several months, have been performed by the care and under the direction of a mixed Commission composed of members of the International Committee and of members of the French section, under the presidency of $M$. Dumas, perpetual secretary to the Academy of Sciences, which represents France on the Committee. The fabrication of the national standards is in course of execution, and the definitive comparisons will shortly be able to be entered on.

\section{NOTES}

WE regret to announce the death of Dr. Oswald Heer of Zurich, the well-known palaontologist, at the age of seventy-five years. In his earlier years Dr. Heer devoted himself to entomology. We hope to give some notice of his life and work in our next number.

THE works in connection with the erection of the Ben Nevis Observatory are so far forward that the formal inauguration of the
Observatory was to take place yesterday. With the view of stimulating public interest in the Observatory, there has just been published a small handbook giving an account of its origin, and describing the objects it is intended to promotc. Mr. George Reid, R.S.A., has contributed attractive drawings of Ben Nevis from the sea, and of the Observatory building ; from Dr. Archibald Geilkie have been obtained bird's-eye views of the scenery visible from the mountain top; and there is also inserted an excellent map, in which the new bridle-road is laid down and the configuration of the district indicated by n"merous contour lines. From a statement given as to existing high.level meteorological stations in other parts of the world, it appears that America maintains two such posts-namely, Pike; Peak, I4, 15 feet, and Mount Washington, 6286 feet; while France can claim four, ranging from 3989 to $\mathbf{1 2}, \mathbf{1} 99$ feet ; and Italy three, of which the highest is 8386 , and the lowest 7087 feet. Russia has one as high as 3787 feet, and Switzerland two, of 7505 and 2875 feet respectively. The highest in this island, so far, would seem to be Hawes Junction, I 35 feet, and Dalnaspidal, I450 feet. Ben Nevis gives an elevation of 4406 feet, and, as has been repeatedly explained, important results are expected from the comparisons it will enable meteorologists to make between the state of the atmosphere at that height and the conditions prevailing at sea level. No time will now be lost in commencing the work of the Observatory, which has been intrusted to Mr. R. T. Omond, with Mr. Angus Kankin, and another yet to be appointed, as assistant observers. During the winter months the summit of the Ben may for weeks together be inaccessible; but certain observations will be daily communicated by means of the telegraph now beirg laid by the Post Office.

THE announcement of the publication of the Berlin Catalogue of Zonal Stars will have the effect of postponing the publication of the French catalogue, for which a credit of 400,000 francs had been asked from the Budget Commission.

The President of the Berlin Geological Society has received a telegram from the l'entland Firth announcing the safe return of the German schooner Germania, which carried the German Polar ob erving party from the Gulf of Camberland, where it has spent a year in successful observation and research.

$W_{\mathrm{E}}$ have received a telegram from Herr Augustin Gamel of Copenhagen, in which he informs us that the Dijmpina anchored at Vardö, Norway, on October I1, all being well on board.

TuE Russian Geographical Society is taking an active part in the International Congress which is to be convoked by the United States for the unification of the meridian. Delegates from the Academy of Sciences and from the Russian Ministries of War, and Posts and Telegraphs, will constitute a Committee at St. Petersburg, and the conclusions of this Committee will be supported at Washington by one or more Russian delegates.

WE learn from the annual reports of the West Siberian and East Siberian branches of the Russian Geographical Society (published in the Izvestia) that the East Siberian branch busily continues the exploration of the very rich remains from the stone period around Lake Baikal. The valley of Tunka, which seems to have been an immense workshop for the fabrication of quartz, jade, and nephite implements, has been visited again by M. Vitkovsky, as well as the valley of the Angara. This last consists of a succession of large plains separated by narrow gorges; the former was occupied during the Post Pliocene period by a series of lakes, and subsequently it was the abode of a numerous population of the Stone period. M. Agapitoff discovered also a place on the Steppe of Ust-Unga which must have been a large workshop for the fabrication of stone-implements, pieces of which cover the steppe over a space of more than twelve miles; thousands of implements could be collected 